\title{
Incorporation and Evaluation of Authentic Research Experiences into the Curriculum through Development of a Theory of Action
}

Pamela Brown, Tammie Cumming, New York City College of Technology-CUNY

Joan D. Pasley, Horizon Research, Inc.

\begin{abstract}
A theory of action outlining undergraduate research program inputs and desired outcomes was developed and used to guide implementation of Course-Based Undergraduate Research Experience (CURE) sections and to create assessment tools to measure attainment of program goals in both apprentice-model undergraduate research and CURE. Student survey results for these two research programs were compared and suggest that many aspects of the academic goals such as designing an experiment, using equipment, collecting and analyzing data, and collaborating with others were achieved in both groups. Regarding the relationship with mentors, both groups reported receiving academic advisement in course selection and career options. Students in the apprenticemodel program were more likely to discuss managing time, establishing career goals, networking, applying to graduate school, and building professionalism with their mentors. Students in the apprentice-model program also reported more time working with their research mentor, a higher quality research experience with their mentor, greater gains in communicating research findings, and more confidence in their research ability and future career path, at a statistically significant level. This approach and information may be useful to faculty mentors in improving the undergraduate researcher experience.
\end{abstract}

Keywords: theory of action, apprentice model, coursebased, authentic research experience, undergraduate research

\section{doi: 10.18833/spur/1/1/9}

New York City College of Technology, a branch of the City University of New York (CUNY), is a minority serving, open-access public institution. The college participated in a series of "Institutionalizing Undergraduate Research" workshops for mission-similar institutions focused on leadership and Council on Undergraduate Research (CUR) skills development (NSF 0920275, Elizabeth L. Ambos, principal investigator). A resulting goal was to expand authentic research experiences into the classroom to increase the number of students benefiting from undergraduate research. When the CUNY Central Office of Academic Affairs subsequently released a Student Success Request for Proposals (RFP) in fall 2013, the college successfully applied for funding to support "City Tech: Assessing the Impact of Undergraduate Research on Degree Attainment and Student Success." The project involved three major components:

1. Assessment of student outcomes for the college's Emerging Scholars program, an apprentice-model undergraduate research program in existence since fall 2006. Students in this program receive $\$ 500$ stipends per semester of undergraduate research and are expected to conduct approximately 50 hours per semester of work as well as attend four professional development workshops on topics such as researching in libraries, writing abstracts, preparing posters, and understanding safety and ethics. They also submit an abstract and participate in the college's poster session at the end of each semester.

2. Expansion of Course-Based Undergraduate Research Experiences (CURE) into four laboratory courses and their assessment.

3. Development of a theory of action to guide the design and implementation of the CURE and development of assessment tools.

Previous work has reported on key aspects of CURE (Auchincloss et al.2014). The Course-Based Undergraduate 